\title{
FACTORS AFFECTING HAEMOCYTOMETER COUNTS OF SPERM CONCENTRATION IN HUMAN SEMEN
}

\author{
M. FREUND AND B. GAROL \\ Departments of Physiology and Pharmacology and of Preventive Medicine, \\ New York Medical College, Flower and Fifth Avenue Hospitals, \\ New York, N.Y., U.S.A.
}

(Received 7th September 1963, revised 20th January 1964)

\begin{abstract}
Summary. Each of three technicians made duplicate pipettings from forty-six semen specimens of seven donors and filled two haemocytometer chambers from each pipette. The number of spermatozoa in each of the four large corner squares of the chamber were counted and recorded separately for a total of 2208 counts on 552 chambers. An analysis of variance was made and the percentage variances were calculated. Marked variation was found in counts among technicians and in duplicate counts by the same technician. The technician term and the related technician interaction terms accounted for 14.8 of the total study variance. Approximately one-half of the variance of the haemocytometer technique itself was due to the variance among technicians (57.4\%) and one-half to the variance among duplicate haemocytometer determinations by the same technician $(42 \cdot 6 \%)$. The $95 \%$ confidence interval for haemocytometer counts, among technicians, on a single specimen which is equal to the mean of this study ( 28 million $/ \mathrm{ml}$ ), is $\pm 52 \%$. The variance associated with the haemocytometer technique is large and must be considered in the design and analysis of studies of semen.
\end{abstract}

\section{INTRODUCTION}

The determination of sperm concentration by a single haemocytometer count is the main basis for deciding whether a human semen specimen falls within normal limits and for predicting whether the donor is fertile. Furthermore, a single haemocytometer count has been the standard method for measurement of the sperm concentration of the specimen in most of the research studies on semen production in man. Recently, Freund (1962, 1963) has studied the among-donor and specimens-within-donor variation in human semen specimens and the effects of factors, such as frequency of emission, age of the specimen, and method of specimen collection, on semen characteristics. In these studies, the sperm concentration of a specimen was determined by a single haemocytometer count and it became apparent that very little was known about the accuracy and repeatability of the haemocytometer technique as applied to the counting of human spermatozoa. 
Berkson, Magath \& Hurn (1940) and Biggs \& Macmillan (1948) studied the sources of error involved in erythrocyte counting by haemocytometer and found marked variation among observers, among duplicate pipettes, and among duplicate chambers. Bane (1952), in an investigation of the haemocytometer technique as applied to bull semen, found that $55 \%$ of the variation between duplicate determinations by the same technician was due to sampling and pipetting error and $45 \%$ to chamber and counting error. He reported that the $99 \%$ confidence interval, in a single determination of 1000 spermatozoa per $\mathrm{mm}^{3}$, was \pm 229 spermatozoa. Campbell, Hancock \& Rothschild (1953) and Campbell, Dott \& Glover (1956), counting live and dead ram, boar and bull spermatozoa, reported a significant difference between the estimates made by two experimental workers and set up tables for the determination of $95 \%$ fiducial limits of a single count by one observer.

The general plan of this investigation was to determine what part of the total variance associated with a study of the sperm concentration of human semen specimens is due to the haemocytometer technique, to analyse the variance of the haemocytometer technique itself in order to assess the relative importance of each step in the procedure, and to estimate the confidence interval of a single haemocytometer count in the measurement of sperm concentration. A preliminary report on this work has been published (Freund \& Carol, 1963).

\section{METHODS}

Semen specimens, collected by masturbation into clean dry sputum bottles, were received from regular donors who were young white men and students at this medical college. The three research technicians who made the counts in this study ranged in experience with haemocytometer work from less than 1 year (Technician 1) to more than 3 years (Technicians 2 and 3). Each of the three technicians made two pipettings from every specimen in the study and filled two chambers of a haemocytometer with each pipette. Standard white cell pipettes (Clay-Adams, A-2450) and haemocytometers (Levy chamber with double Neubauer ruling, Clay-Adams, A-2900) were used. The specimen was mixed by swirling, semen was drawn up to the 1 graduation on the pipette $(0.1 \mathrm{ml})$, and the pipette was filled to the top mark with a sperm diluting solution (16 g sodium bicarbonate and $4 \mathrm{~g}$ phenol in $400 \mathrm{ml}$ distilled water). The pipette was shaken in an electrical shaker for 30 secs, the first few drops were discarded, and both chambers of a haemocytometer were filled from the pipette. The cells were allowed to settle and were counted under low power $(\times 150)$ of the microscope. The number of spermatozoa in each of the four large corner squares of the chamber were counted and recorded separately. The technicians had no knowledge of each other's counts during the course of the determinations.

An analysis of variance was made on thirty-six specimens (the first six specimens from Donors 1, 2, 3 and 5, 6, 7, Table 1) in order to avoid the difficulties inherent in an analysis of data with unequal subclass numbers. A preliminary examination of the data confirmed that they were distributed in Poisson fashion with variance proportional to the mean. Therefore, the data 
were transformed to the square roots of the counts. The statistical analyses followed the procedures outlined by Snedecor (1956).

\section{RESULTS}

A comparison of the means by donors for sperm concentration, as determined by the three technicians, indicates a large order of difference (Table 1). It is evident that the means calculated from the counts made by Technician 1 were consistently lower than the means derived from the counts made by the other two technicians. Although the total study means for sperm concentration produced by Technicians 2 and 3 were quite close to each other, there were marked differences between them in means by donor (Table 1).

TABLE 1

COMPARISON OF HAEMOCYTOMETER COUNTS OF SPERM CONCENTRATION; VARIATION IN COUNTS AMONG TECHNICIANS

\begin{tabular}{|c|c|c|c|c|}
\hline \multirow{2}{*}{$\begin{array}{l}\text { Donor } \\
\text { No. }\end{array}$} & \multirow{2}{*}{$\underset{\text { specimens }}{\text { No. }}$} & \multicolumn{3}{|c|}{ Sperm concentration $\left(\times 10^{6} / \mathrm{ml}\right)$} \\
\hline & & $\begin{array}{c}\text { Technician } \\
1\end{array}$ & $\begin{array}{c}\text { Technician } \\
2\end{array}$ & $\begin{array}{c}\text { Technician } \\
3\end{array}$ \\
\hline \multirow[t]{2}{*}{$\begin{array}{l}1 \\
2 \\
3 \\
4 \\
5 \\
6 \\
7\end{array}$} & $\begin{array}{l}7 \\
8 \\
8 \\
2 \\
8 \\
7 \\
6\end{array}$ & $\begin{array}{l}22 \cdot 452 \\
23 \cdot 438 \\
12 \cdot 161 \\
26 \cdot 275 \\
24 \cdot 242 \\
28 \cdot 657 \\
27 \cdot 410\end{array}$ & $\begin{array}{l}36 \cdot 007 \\
30 \cdot 872 \\
12 \cdot 602 \\
32 \cdot 994 \\
37 \cdot 975 \\
38 \cdot 393 \\
29 \cdot 331\end{array}$ & $\begin{array}{l}32 \cdot 100 \\
38 \cdot 483 \\
14 \cdot 126 \\
38 \cdot 794 \\
35 \cdot 152 \\
37 \cdot 793 \\
33 \cdot 488\end{array}$ \\
\hline & 46 & $22 \cdot 946^{*}$ & $30 \cdot 747^{*}$ & $31 \cdot 953^{*}$ \\
\hline
\end{tabular}

* Weighted means.

A comparison of the mean differences in sperm concentration, as determined by the three technicians, indicates that there was considerable variation in counts not only among technicians but also between duplicate pipettings and between duplicate chamber counts by the same technician (Table 2). Since the mean differences between duplicate pipettes and between duplicate chambers were each about $10 \%$ of the mean sperm concentration, it is evident that mean differences of the order of $20 \%$ in sperm concentration may be expected between duplicate determinations by the same technician.

An examination of the summary of the statistical analysis (Table 3) shows that, as expected, there was a significant difference among donors and among specimens within donor and that $78 \%$ of the total study variance was due to these two factors. The relatively low mean sperm concentrations (Table 1) and the relatively small donor percentage variance term (Table 3 ) were most probably due to the fact that, at the time that this study was made, the donors were participating in a concurrent study which required very frequent emission (Freund, 1963).

It is also apparent (Table 3) that there were significant differences among technicians and that these differences accounted for $6 \%$ of the variance of the study. Evidently, the technicians also differed markedly in their handling of 
specimens of low sperm count as compared to specimens of high count, since the TD and TS(D) terms are both statistically significant. The technician term (T) and the related technician interaction terms $(\mathrm{TD}, \mathrm{TS}(\mathrm{D})$ ) accounted for $14.8 \%$ of the total study variance.

\section{TABLE 2}

COMPARISON OF MEAN DIFFERENCES IN HAEMOCYTOMETER COUNTS OF SPERM CONCENTRATION AMONG TEGHNICIANS, BETWEEN DUPLICATE PIPETTINGS, AND BETWEEN DUPLICATE GHAMBERS

\begin{tabular}{|c|c|c|c|c|c|}
\hline \multirow{2}{*}{$\begin{array}{c}\text { Donor. } \\
\text { No. }\end{array}$} & \multirow{2}{*}{$\begin{array}{c}\text { No. } \\
\text { specimens }\end{array}$} & \multirow{2}{*}{$\begin{array}{c}\text { Mean } \\
\text { sperm } \\
\text { conc. } \\
\left(\times 10^{8} / \mathrm{ml}\right)\end{array}$} & \multicolumn{3}{|c|}{ Mean differences in sperm conc. $\left(\times 10^{6} / \mathrm{ml}\right)$} \\
\hline & & & $\begin{array}{c}\text { Among } \\
\text { technicians }\end{array}$ & $\begin{array}{c}\text { Between } \\
\text { duplicate } \\
\text { pipettings }\end{array}$ & $\begin{array}{l}\text { Between } \\
\text { duplicate } \\
\text { chambers }\end{array}$ \\
\hline \multirow[t]{2}{*}{$\begin{array}{l}1 \\
2 \\
3 \\
4 \\
5 \\
6 \\
7\end{array}$} & $\begin{array}{l}7 \\
8 \\
8 \\
2 \\
8 \\
7 \\
6\end{array}$ & $\begin{array}{l}30 \cdot 186 \\
30 \cdot 931 \\
12.963 \\
33 \cdot 021 \\
32 \cdot 456 \\
34.948 \\
30 \cdot 076\end{array}$ & $\begin{array}{r}11 \cdot 109 \\
1.052 \\
1 \cdot 813 \\
8 \cdot 142 \\
9.909 \\
9 \cdot 026 \\
5 \cdot 551\end{array}$ & $\begin{array}{l}3 \cdot 719 \\
3 \cdot 184 \\
1.446 \\
2 \cdot 504 \\
2 \cdot 469 \\
3 \cdot 112 \\
4 \cdot 070\end{array}$ & $\begin{array}{l}4 \cdot 007 \\
3 \cdot 747 \\
2 \cdot 075 \\
3 \cdot 430 \\
4 \cdot 056 \\
3 \cdot 427 \\
4 \cdot 381\end{array}$ \\
\hline & 46 & $28.549 *$ & $8 \cdot 008 *$ & $2 \cdot 914^{*}$ & $3.570^{*}$ \\
\hline
\end{tabular}

* Weighted means.

TABLE 3

ANALYSIS OF VARIANCE OF AND ESTIMATED VARIANCES FOR SPERM CONCENTRATION DETERMINATIONS

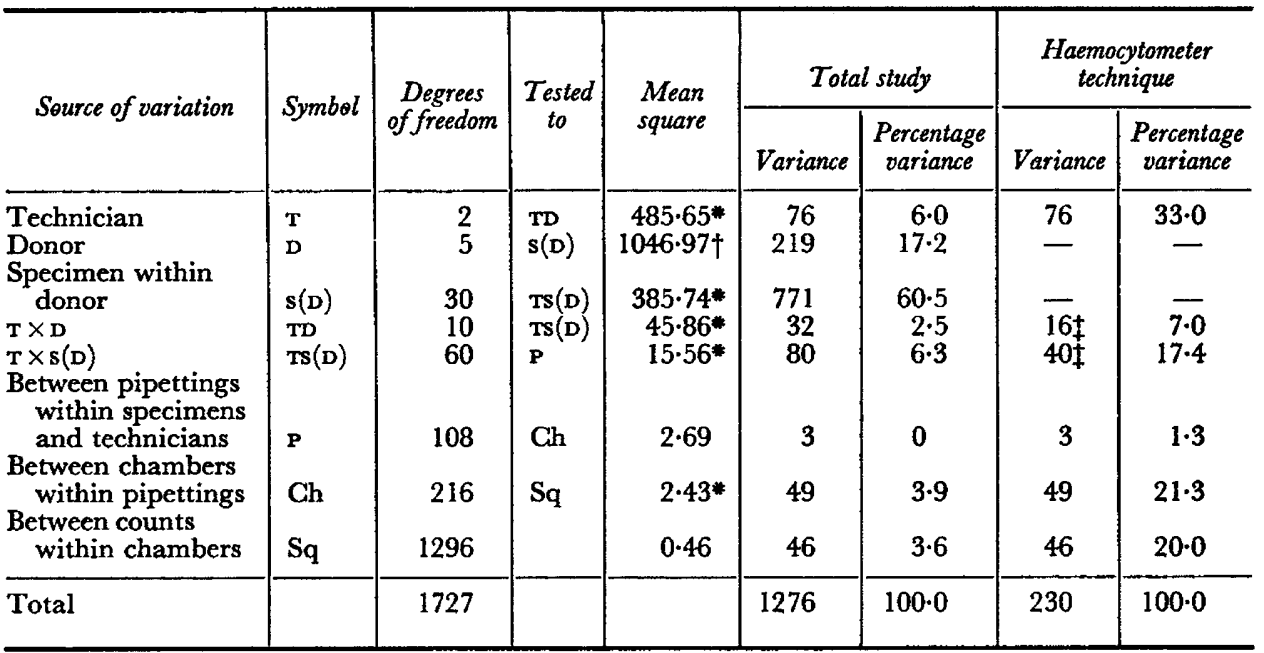

* Statistically significant $(P<0 \cdot 01)$.

+ Statistically significant $(P<0 \cdot 05)$.

I TD of technique is taken as one-half of total-study TD; TS(D) of technique is taken as one-half of total study Ts(D).

When only the variance of the haemocytometer technique itself is considered (Table 3), it becomes apparent that approximately one-half of the variance of 
the technique is due to the variance among technicians $(57.4 \%)$ and one-half to the variance among duplicate haemocytometer determinations by the same technician $(42 \cdot 6 \%)$.

\section{DISCUSSION}

These data demonstrate that there is a large amount of variation among technicians and within technicians in the determination of sperm concentration by counting in the haemocytometer. This is particularly striking in view of the fact that the three technicians who participated in this study were trained in the same laboratory and used the same methods and equipment. The technicians were also aware of the fact that they were participating in a study of their technique and it is most probable that they made every effort to achieve the most accurate results possible, within the limitations of their training and abilities. The possibility that an unconscious bias was present cannot be discounted, since each technician was aware that she was counting the same specimen four times and there might have been a tendency to make the counts closer to each other than might have been the case if the technician was not aware that the four counts were being made on the same specimen. While such a bias might affect the variability of the counts of the same specimen by each technician, there would be no such effect on the variability of counts among technicians.

When the technician error is converted to a confidence statement, it may be stated that the $95 \%$ confidence interval for haemocytometer counts, among technicians, on a single semen specimen which is equal to the mean of this study, is $\pm 52 \%$. In other words, when two technicians count the same semen specimen, $95 \%$ of the time the second count will be within $\pm 52 \%$ of the first, and $5 \%$ of the time the second count will be more than $\pm 52 \%$ of the first. It is suggested that the differences in haemocytometer counts among technicians working in different laboratories would be of this magnitude or greater.

It is apparent from these data that there is need for extreme caution in comparing the experimental results from two laboratories in studies of sperm production, based on haemocytometer counts made in the different laboratories, since a considerable part of such apparent differences may be due to variation among technicians in counts. This variation among technicians could become a serious problem in co-operative studies among two or more laboratories and every attempt should be made to standardize the haemocytometer technique before such studies are started.

It is also of importance to consider the variance among technicians within the same laboratory when more than one technician works on the same study. It would be preferable to have one technician do all of the haemocytometer counts for one study, but, if this is impractical, care should be taken so that the specimens are randomly assigned to the technicians for counting. If this is not done, a greater systematic error among technicians could be built into the study due to the differences among technicians in haemocytometer technique.

The variance among technicians in the same laboratory or among technicians in different laboratories is large and of evident importance and confirms the 
report of Campbell et al. (1956), who found that a significant difference existed between the estimates of live-dead counts of bull spermatozoa made by two workers. This variance must be considered in the design of the experiment when it is planned to test treatment differences in the statistical analyses of such studies.

Not so evident, however, is the variance among duplicate determinations by the same technician on the same specimen. These data indicate that mean differences of the order of $20 \%$ may be expected between duplicate determinations by the same technician. The variance, among duplicate determinations by the same technician, encountered when counting human spermatozoa is very similar to that reported by Berkson et al. (1940) for leukocytes and by Bane (1952) for bull spermatozoa. This variability must be considered as part of the experimental error, since all the steps in the technique are involved (Table 3) and since significant technician-specimen and technician-donor effects exist. These data support the earlier reports (Freund, 1962, 1963) that a single semen specimen cannot be used to estimate the level of a donor's semen production with an accuracy suitable for research purposes. This is particularly true when the sperm concentration has been determined by a single count in the haemocytometer, since the variance of the technique is incorporated in the estimate.

In studies where a very accurate determination of the sperm concentration of each semen specimen is critical, e.g. in the calibration of a photometer for bull sperm concentration determinations (Salisbury, Beck, Elliot \& Willett, 1943) or in the development of a method for the estimation of bull sperm concentration by packed cell volume (Foote, 1958) at least two well-trained technicians should do the haemocytometer counts and duplicate pipettes and chambers should be used by each technician. Since the repeatability of duplicate photometric determinations of sperm concentration is so high, it is not usually emphasized that the calibration of the photometer is based on haemocytometer counts and that the variance associated with such counts is incorporated into the photometer method.

In a study where the treatment effect on sperm concentration is expected to be small, the variance of the technique might be critical. The most practical single step to decrease the variance associated with the haemocytometer technique would be to load and count duplicate chambers from each pipette. In any case, the variance associated with the technique must either be reduced to a negligible level or else it must be accounted for in the statistical analysis of the data.

\section{ACKNOWLEDGMENTS}

This investigation was supported by RG-06014-05 and, in part, by RG-06880-04, National Institute of General Medical Sciences, National Institutes of Health, United States Public Health Service. We wish to thank Mrs Gloria Edwards, Miss Sandra Frank and Miss Beatrice Keshner for their technical assistance. The senior author is a Career Scientist of the Health Research Council of the City of New York (1-218). 


\section{REFERENCES}

BANE, A. (1952) A study on the technique of hemocytometric determination of sperm motility and sperm concentration in bull semen. Comell Vet. 42, 518.

Berkson, J., Magath, T. B. \& Hurn, M. (1940) Error of estimate of the blood cell count as made in the hemocytometer. Amer. F. Physiol. 128, 309.

Biggs, R. \& MAcmillan, R. L. (1948) The errors of some haematological methods as they are used in a routine laboratory. F. clin. Path. 1, 269.

Campbell, R. C., DotT, H. M. \& Glover, T. D. (1956) Nigrosin eosin as a stain for differentiating live and dead spermatozoa. 7. agric. Sci. 48, 1 .

Gampbeli, R. G., Hancock, J. L. \& Rothschild, Lord (1953) Counting live and dead bull spermatozoa. F. exp. Biol. 30, 44.

Foote, R. H. (1958) Estimation of bull sperm concentration by packed cell volume. F. Dairy Sci. 41, 1109.

FrEUND, M. (1962) Interrelationships among the characteristics of human semen and factors affecting semen specimen quality. F. Reprod. Fertil. 4, 143.

FrEUND, M. (1963) Effect of frequency of emission on semen output and an estimate of daily sperm production in man. F. Reprod. Fertil. 6, 269.

FreUnd, M. \& CAROL, B. (1963) Variance associated with determination of sperm concentration of human semen by hemocytometer count. Fed. Proc. 22, 569.

Salisbury, G. W., Beck, G. H., Elliot, J. \& Willett, E. L. (1943) Rapid methods for estimating the number of spermatozoa in bull semen. F. Dairy Sci. 26, 69.

SNedecor, G. W. (1956) Statistical methods, 5th edn. Iowa State College Press, Ames. 